\title{
PLANTAS DE COBERTURA, SUCESSÃO DE CULTURAS E MANEJO DO SOLO EM FEIJOEIRO ( $\left.{ }^{\mathbf{1}}\right)$
}

\author{
MARCO ANTONIO CAMILLO DE CARVALHO $\left({ }^{\bullet}\right)$; ROGÉRIO PERES SORATTO $\left({ }^{3}\right)$; \\ MARLENE CRISTINA ALVES $\left({ }^{4,6}\right)$; ORIVALDO ARF $\left({ }^{5,6}\right)$; MARCO EUSTÁQUIO DE SÁ $\left({ }^{5}\right)$
}

\begin{abstract}
RESUMO
Plantas de cobertura, sucessão de cultivos e manejo conservacionistas do solo são práticas que visam à preservação ambiental e à sustentabilidade dos sistemas de produção de grãos. O objetivo deste trabalho foi avaliar a influência das plantas de cobertura, culturas antecessoras e sistemas de manejo do solo no acúmulo de nutrientes, características agronômicas e produtividade do feijoeiro cultivado no outono-inverno. O experimento foi realizado em Latossolo Vermelho distrófico. O delineamento utilizado foi o de blocos ao acaso, em esquema de parcela subsubdividida e quatro repetições. Nas parcelas, utilizaram-se quatro plantas de cobertura e pousio (outubro-dezembro). Nas subparcelas, foram adotados dois sistemas de manejo do solo: sistema de plantio direto recém-implantado e preparo convencional (uma gradagem pesada + duas gradagens leves). Nas subsubparcelas, foram utilizadas três culturas antecessoras ao feijoeiro, (dezembro a maio). As plantas de cobertura influenciaram o acúmulo de nutrientes, mas não interferiram nas características agronômicas e produtividade do feijoeiro. A produtividade do feijoeiro foi maior na sucessão à cultura da soja, que em sucessão ao algodão ou milho.
\end{abstract}

Palavras-chave: Phaseolus vulgaris, rotação de culturas, plantio direto.

\section{ABSTRACT \\ COVER PLANTS, CROP SUCCESSION AND SOIL MANAGEMENT OF COMMON BEAN}

Cover plants, succession of different crops and conservation management of soil aim the environmental preservation and system of crop grain production support. The objective of this work was to evaluate the influence of cover plants, previous crop and soil management on nutrient uptake, agronomical characteristics and grain yield of common bean cultivated during fall-winter. The experiment was carried out in a Typic Hapludox soil. The experimental design used was that of randomized blocks, in a split-split plot scheme, with four replications. Four cover plant and fallow (October-December) were been used in plots. In subplots, two soil management systems were used: no-tillage in implantation phase and conventional tillage (one disk harrow + two levelling harrow). In subsubplots, were growth three previous crops before bean (December to May). The cover plants had influence nutrients uptake but have not affected the agronomical characteristics and grain yield. The common bean grain yield was larger in succession soybean crop than in succession cotton or mayze crops.

Key words: Phaseolus vulgaris, crop rotation, no-tillage.

( $\left.{ }^{1}\right)$ Recebido para publicação em 23 de janeiro de 2006 e aceito em 11 de junho de 2007.

$\left({ }^{2}\right)$ Universidade do Estado do Mato Grosso (Unemat), Rod. MT 208, km 147, Caixa Postal 324, 78580-000 Alta Floresta (MT). E-mail: marcocarvalho@unemat.br $\left(^{*}\right)$ Autor correspondente.

$\left({ }^{3}\right)$ Departamento de Produção Vegetal, Universidade Estadual Paulista (UNESP), Faculdade de Ciências Agronômicas, Fazenda Experimental Lageado, Caixa Postal 237, 18610-307 Botucatu (SP). E-mail: soratto@fca.unesp.br

$\left({ }^{4}\right)$ Departamento de Fitossanidade, Engenharia Rural e Solos, Universidade Estadual Paulista (UNESP), Faculdade de Engenharia, Caixa Postal 31, 15385-000 Ilha Solteira (SP). E-mail: mcalves@agr.feis.unesp.br.

$\left({ }^{5}\right)$ Departamento de Fitotecnia, Tecnologia de Alimentos e Sócio-Economia - FEIS/UNESP, SP. E-mail: arf@agr.feis.unesp.br; mesa@agr.feis.unesp.br.

$\left({ }^{6}\right)$ Com bolsa de produtividade em pesquisa do CNPq. 


\section{INTRODUÇÃO}

Com a opção de cultivo no período de outonoinverno, sob irrigação, a cultura do feijoeiro tem sido implantada em novas áreas, principalmente nas regiões Noroeste de São Paulo, Sul de Mato Grosso, Goiás, Minas Gerais, Tocantins e Mato Grosso do Sul. O cultivo irrigado proporciona produto de qualidade superior, no período da entressafra, quando alcança melhores preços, estimulando o agricultor a utilizar a melhor tecnologia, obtendo produtividade cerca de três vezes superior às obtidas em outras épocas de cultivo (CONAB, 2005). No entanto, tem-se observado sinais de desequilíbrio ambiental e, conseqüentemente, prejuízos à produtividade das culturas, evidenciando a necessidade de reavaliação das práticas agrícolas adotadas, além do conhecimento de estratégias racionais de manejo.

No Cerrado, como nas demais regiões tropicais, a mineralização da matéria orgânica é bastante rápida, por causa da elevada temperatura e umidade do solo, durante boa parte do ano (SANCHEZ e LogAN, 1992). Essa característica impossibilita a adequada reposição de nutrientes nos sistemas convencionais de manejo dos solos e das culturas. Nessa situação, a rotação de culturas e as plantas de cobertura, podem influenciar positivamente a produtividade do feijoeiro (WUTKE et al., 1998).

A sucessão de cultivos tem sido destacada por promover melhorias às condições físicas, químicas e biológicas do solo, como proteção contra erosão, maior espaço poroso e da taxa de infiltração de água e aumento da capacidade de retenção de água, incremento da capacidade de reciclagem e mobilização de nutrientes lixiviados ou pouco solúveis em camadas mais profundas do solo (IGUE, 1984). Além disso, propicia melhor aproveitamento de adubos químicos e redução nos custos com adubação mineral, uma vez que promove aumento da atividade biológica do solo (HERNANi et al., 1995), promovendo o controle de plantas daninhas e dos patógenos das plantas cultivadas.

A manutenção de resíduos culturais na superfície do solo proporciona maior proteção do solo contra o impacto direto das chuvas (IGUE, 1984), favorece a infiltração e reduz a perda de água por escorrimento e perda de solo por erosão (HERMANI et al., 1997; Stone e Silveira, 1999). O menor revolvimento do solo leva à decomposição mais lenta do material orgânico, tendo como conseqüência a melhoria das condições físicas, químicas e biológicas no solo, que vão repercutir em sua fertilidade e na produtividade das culturas (WUTKE, 1993). Além disso, fatores como temperatura e cobertura superficial têm, em muitas situações, disponibilizado mais água às plantas em solos sob sistema de plantio direto, influenciando diretamente a economia de água, o desenvolvimento e a produtividade das culturas (Stone e Silveira, 1999).

Na cultura do feijoeiro, os resultados são contrastantes no que se refere ao manejo do solo. De acordo com SiLva et al. (2004) e SiLVA (2005), não há diferença na produtividade de grãos do feijoeiro entre diversos sistemas de manejo do solo (convencional, mínimo e direto). KLuthCousKi et al. (2000); SiLVEIRA et al. (2001) e SoratTo et al. (2003) obtiveram melhores resultados quando a leguminosa foi cultivada sobre solo com preparo convencional. No entanto, em muitas situações tem sido possível obter maiores produtividades em sistema de plantio direto (URCHEI, 1996; Stone e Silveira, 1999). Segundo Stone e Moreira (2001), a produtividade do feijoeiro sob sistema de plantio direto aumenta com o passar do tempo.

O objetivo deste trabalho foi avaliar a influência das plantas de cobertura de primavera, culturas antecessoras e manejo do solo no acúmulo de nutrientes, características agronômicas e produtividade do feijoeiro de inverno, em solo de cerrado.

\section{MATERIAL E MÉTODOS}

O experimento foi realizado em área experimental da Faculdade de Engenharia de Ilha Solteira da Universidade Estadual Paulista - UNESP, no Município de Selvíria (MS), em longitude de $51^{\circ}$ $22^{\prime} \mathrm{W}$ e a latitude de $20^{\circ} 22^{\prime} \mathrm{S}$, com $335 \mathrm{~m}$ de altitude e clima do tipo Aw (Köppen), precipitação pluvial média anual de $1.156 \mathrm{~mm}$, concentrada, principalmente no período de outubro a março, temperatura média anual de $25,2{ }^{\circ} \mathrm{C}$, e média anual de umidade relativa do ar entre $70 \%$ e $80 \%$ (EMBRAPA, 2007).

O solo do experimento é Latossolo Vermelho distrófico típico argiloso (DematTê, 1980). Em maio de 1997, coletou-se uma amostra composta de 10 subamostras da parte superficial na profundidade de 0-0,20 m, cujas características químicas foram: matéria orgânica, 27,0 $\mathrm{g} \mathrm{dm}^{-3}, \mathrm{pH}\left(\mathrm{CaCl}_{2}\right), 5,3 ; \mathrm{P}, 13,0 \mathrm{mg} \mathrm{dm}^{-}$ ${ }^{3}$; $\mathrm{K}, \mathrm{Ca}$ e $\mathrm{Mg}, 1,1,28,0$ e 10,3 $\mathrm{mmol}_{\mathrm{c}} \mathrm{dm}^{-3}$, respectivamente, e saturação por bases de $57 \%$.

O delineamento experimental utilizado foi o de blocos ao acaso, em esquema de parcelas subsubdivididas, com quatro repetições.

As parcelas foram constituídas por quatro espécies de plantas de cobertura: mucuna-preta (Mucuna aterrima (Piper \& Tracy) Merr.); guandu (Cajanus cajan (L.) Millsp.); crotalária (Crotalaria juncea 
L.); milheto (Pennisetum americanum L.) e área de pousio (vegetação espontânea), cultivados na primavera (outubro-novembro). Cada parcela teve a dimensão $42 \times 6 \mathrm{~m}$, espaçadas umas das outras em 7 metros. $\mathrm{Na}$ área em pousio, predominavam espécies como Panicum maximum (Jacq.) e Brachiaria decumbens (Stapf.) Prain.

As subparcelas foram constituídas pelos dois sistemas de manejo do solo: sistema de plantio direto (semeadura sem preparo prévio do solo) e sistema de preparo convencional (preparo do solo com grade pesada à profundidade de $0,15-0,20 \mathrm{~m}$ e gradagens com grade leve na camada de $0,12 \mathrm{~m}$. Cada subparcela teve a dimensão $21 \times 6 \mathrm{~m}$.

As subsubparcelas, com dimensão de $7 \times 6 \mathrm{~m}$, foram constituídas pelas culturas de verão, cultivadas de dezembro a maio: algodão, soja e milho. A área útil da subsubparcela foi constituída pela porção central, desprezando-se $1,0 \mathrm{~m}$ nas laterais e $0,5 \mathrm{~m}$ nas extremidades perfazendo uma área de $25 \mathrm{~m}^{2}(5 \times 5 \mathrm{~m})$.

Visando à uniformização da área e romper camadas compactadas para dar início ao experimento, o solo da área experimental, anteriormente cultivado com arroz, foi preparado mediante uma aração, com arado de discos reversíveis, à profundidade de 0,20$0,25 \mathrm{~m}$ e duas gradagens, com grade leve à profundidade de $0,10-0,12 \mathrm{~m}$, sendo a primeira após a aração em 30/04/1997 e, a segunda em 15/5/1997. Após o preparo do solo, o feijoeiro foi semeado na área a ser instalado o experimento.

A pesquisa teve início em outubro de 1997, após a colheita do feijoeiro, onde nas áreas destinadas ao sistema de plantio direto, aplicou-se o herbicida glifosato (2.400 $\mathrm{g} \mathrm{ha}^{-1}$ do i.a.). O restante da área recebeu preparo de solo convencional.

A semeadura das plantas de cobertura foi realizada em 19/10/1997 e 8/10/1998, em sucessão ao feijoeiro. O espaçamento e a densidade de semeadura utilizados foram os seguintes: $0,45 \mathrm{~m}$ de entrelinhas e cinco sementes por metro para a mucuna-preta; $0,45 \mathrm{~m}$ de entrelinhas e 30 sementes por metro para a crotalária e o guandu e $0,225 \mathrm{~m}$ de entrelinhas e 120 sementes por metro para o milheto. Todas as espécies foram semeadas sem adubação básica ou de cobertura. Em 17/12/1997 e 21/12/1998, nas áreas destinadas ao sistema de plantio direto, a vegetação foi dessecada mediante aplicação de herbicida glifosato. Nas áreas destinadas ao sistema convencional a vegetação foi roçada e o solo preparado, como descrito anteriormente, sendo suficiente para a incorporação de grande parte dos resíduos vegetais presentes na superfície do solo.
Antes do manejo das plantas de cobertura e área de pousio foram coletadas amostras de plantas em $1,0 \mathrm{~m}^{2}$ de cada subsubparcela e determinada a produção de massa seca. Foram obtidas as seguintes produções de massa seca: 4.333, 2.856, 10.024, 6.047 e $4.660 \mathrm{~kg} \mathrm{ha}^{-1} \mathrm{em} 1997$ e $4.883,2.900,10.316,4225$ e $4.783 \mathrm{~kg} \mathrm{ha}^{-1}$ em 1998, respectivamente, para mucuna, guandu, milheto, crotalária e pousio.

O algodão foi semeado em 20/12/1997 e 28/ $12 / 1998$, utilizando-se a cultivar IAC 22 , com nove sementes viáveis por metro de sulco e $0,90 \mathrm{~m}$ entrelinhas. A adubação básica foi realizada segundo as recomendações de RAIJ et al. (1996), sendo utilizado $375 \mathrm{~kg} \mathrm{ha}^{-1} \mathrm{da}$ fórmula NPK 08-28-16, nas duas safras. A adubação de cobertura, nos dois anos agrícolas, constou de $50 \mathrm{~kg} \mathrm{ha}^{-1}$ de $\mathrm{N}$ (sulfato de amônio). O fim das colheitas do algodão ocorreu em 7/5/1998 e 5/ $5 / 1999$, produzindo, respectivamente, a média de 1.351 e $2.548 \mathrm{~kg} \mathrm{ha}^{-1}$.

O milho foi semeado em 7/1/1998 e 28/12/ 1998, utilizando-se o híbrido Exceler, com seis sementes por metro de sulco e $0,90 \mathrm{~m}$ entrelinhas. A adubação básica (RAIJ et al., 1996) foi de $285 \mathrm{~kg} \mathrm{ha}^{-1}$ da fórmula NPK 08-28-16, nas duas safras. Efetuouse a adubação em cobertura com 50 e $60 \mathrm{~kg} \mathrm{ha}^{-1}$ de N na forma de sulfato de amônio, nos dois anos agrícolas. As colheitas do milho foram realizadas em 15/5/1998 e 23/4/1999, sendo produzidos, respectivamente, 6.959 e $4.489 \mathrm{~kg} \mathrm{ha}^{-1}$.

A soja foi semeada em $7 / 1 / 1998$ e $28 / 12 /$ 1998, utilizando-se a cultivar IAC 17 na safra 1997/ 98 e FT cristalina na safra 1998/99, com 25 sementes por metro de sulco e $0,45 \mathrm{~m}$ entrelinhas, com as sementes submetidas à inoculação com Bradyrhizobium japonicum.

A adubação básica (RAIj et al., 1996) foi de 250 $\mathrm{kg} \mathrm{ha}^{-1} \mathrm{da}$ fórmula-NPK 08-28-16, nas duas safras. A utilização da dose de arranque de $20 \mathrm{~kg} \mathrm{ha}^{-1}$ de N ocorreu por se tratar de uma área sem histórico anterior de cultura de soja e em virtude da incorporação e/ou dessecação das plantas de cobertura, evitando a competição inicial entre microrganismos e planta. A soja foi colhida em 15/ 5/1998 e 9/5/1999, produzindo, respectivamente, 1.771 e $2.594 \mathrm{~kg} \mathrm{ha}^{-1}$.

Após a colheita de todas as culturas de verão, nos dois anos agrícolas, realizou-se a roçada dos restos culturais. Nas áreas destinadas ao sistema de plantio direto aplicou-se o herbicida glifosato $(2.400$ $\mathrm{g} \mathrm{ha}^{-1}$ do i.a.) e nas áreas de preparo convencional foi realizado o preparo do solo, como já havia sido realizada para a instalação das plantas de cobertura e as culturas de verão. 
A semeadura do feijoeiro foi realizada em 10/ 6/1998 e 16/6/1999, utilizando-se a cultivar IAC Carioca, em 1998, e Pérola, em 1999, com 16 sementes por metro e espaçamento entrelinhas de $0,50 \mathrm{~m}$. A adubação básica no sulco de semeadura foi de $240 \mathrm{~kg}$ ha $^{-1}$ da fórmula 02-20-20 e aos 25 dias após a emergência das plântulas realizou-se a adubação de cobertura aplicando-se $50 \mathrm{~kg} \mathrm{ha}^{-1}$ de $\mathrm{N}$ (sulfato de amônio), nos dois anos de cultivo, conforme recomendação de RAIJ et al. (1996). Os tratamentos fitossanitários foram feitos de acordo com as recomendações para cada cultura.

A cultura do feijoeiro foi irrigada por um sistema de aspersão convencional, de acordo com o estádio e necessidade hídrica da cultura.

No florescimento, coletou-se a parte aérea de 10 plantas na área útil de cada subsubparcela. O material foi lavado em água destilada com pouco de detergente, enxaguado com água destilada e seco em estufa a $65{ }^{\circ} \mathrm{C}$, até obter-se massa constante. Em seguida, as plantas foram pesadas, para determinação da massa seca, moídas e submetidas à análise para determinação dos teores dos nutrientes $(\mathrm{N}, \mathrm{P}, \mathrm{K}, \mathrm{Ca}$, Mg, S), segundo Malavolta et al. (1997).

Para a avaliação da produtividade de grãos, foram colhidas em 11/9/1998 e 13/9/1999, três linhas no centro da área útil de cada subsubparcela. Nessa ocasião, também foi determinada a população de plantas, nas três linhas do centro de cada subsubparcela e coletadas 10 plantas por unidade experimental, nas quais foram determinados: a altura de planta e de inserção da primeira vagem, o número de vagens por planta, o número médio de grãos por vagem e a massa de cem grãos. O teor de água dos grãos foi corrigido para $130 \mathrm{~g} \mathrm{~kg}^{-1}$.

Um mês após a colheita do feijoeiro foi determinado em cada subsubparcela, a densidade do solo, pelo método do anel volumétrico e mesa de tensão (KIEHL, 1979), nas profundidades de $0-0,1 ; 0,1$ 0,2 e $0,2-0,4 \mathrm{~m}$.

Os resultados foram submetidos à análise de variância em cada ano agrícola. Quando não houve interação significativa entre os fatores, foram comparados apenas os efeitos isolados de cada fator. As médias foram comparadas pelo teste de Tukey a $5 \%$ de probabilidade.

\section{RESULTADOS E DISCUSSÃO}

Optou-se por não realizar a análise conjunta, uma vez que foram utilizadas cultivares diferentes nos dois anos agrícolas, o que poderia levar a interpretações equivocadas dos resultados.
As plantas de cobertura não influenciaram o acúmulo de massa seca na parte aérea das plantas de feijoeiro, nos dois anos de cultivo (Tabela 1). O cultivo na primavera, de mucuna-preta, no primeiro, e guandu no segundo ano, proporcionaram maiores teores de $\mathrm{N}$ na parte aérea do feijoeiro cultivado no outono-inverno seguinte. ARF et al. (1999) também verificaram maior teor de $\mathrm{N}$ na parte aérea do feijoeiro cultivado após leguminosas (mucuna-preta e lablabe). Os teores de P não foram afetados pelas plantas de cobertura.

O cultivo do feijoeiro em sucessão ao milheto proporcionou maior absorção de $\mathrm{K}$, diferindo do pousio em 1998, e do pousio, guandu e mucuna-preta em 1999. Salton e Hernani (1994) observaram que o milheto acumula grande quantidade de $\mathrm{K}$ na parte aérea $\left(377 \mathrm{~kg} \mathrm{ha}^{-1}\right)$, disponibilizando para as culturas subseqüentes. A mucuna-preta promoveu maior absorção de Ca na parte aérea do feijoeiro, em 1998, porém, diferindo apenas da crotalária em 1999. O guandu, em 1998, e a crotalária, em 1999, proporcionaram a maior absorção de $\mathrm{Mg}$ na parte aérea do feijoeiro, já a mucuna-preta proporcionou o menor absorção desse nutriente, nos dois anos de cultivo. A absorção de $S$ no feijoeiro não foi influenciado pelas espécies de plantas de cobertura de primavera, a exemplo do verificado por ARF et al. (1999).

O sistema de plantio direto recém-implantado proporcionou maior teor de $\mathrm{N}$ na parte aérea do feijoeiro, porém, com efeito significativo apenas no segundo ano de cultivo (Tabela 1). A cobertura com restos de culturas tem, em muitas situações, disponibilizado mais água às plantas em solos sob sistema de plantio direto (Stone e Silveira, 1999), o que pode ocorrer mesmo em sistemas irrigados. Em virtude desse fato, esse sistema pode ter contribuído para a maior eficiência de utilização do $\mathrm{N}$ aplicado em cobertura, pois o nitrato entra em contato com as raízes por fluxo de massa. Foram observados maiores teores de $\mathrm{P} \mathrm{e} \mathrm{Ca}$, em ambos os anos, e de $\mathrm{Mg}$ em 1999, na parte aérea do feijoeiro cultivado sob sistema de plantio direto recém-implantado (Tabela 1). No sistema de plantio direto, o não-revolvimento, a manutenção e a gradual decomposição dos restos de culturas na superfície do solo resultam em menor perda de solo por erosão, menor mistura dos fertilizantes com o solo e, em conseqüência, no acúmulo de $\mathrm{P}$, K, Ca e Mg na camada superficial, além da manutenção do $\mathrm{P}$ em forma disponível por maior período devido à competição de compostos orgânicos pelos sítios de adsorção (RHEINHEIMER et al., 1998). O sistema de manejo do solo não interferiu nos teores de $\mathrm{K}$ e $\mathrm{S}$ pelo feijoeiro, corroborando os resultados obtidos por Silva (2005). 


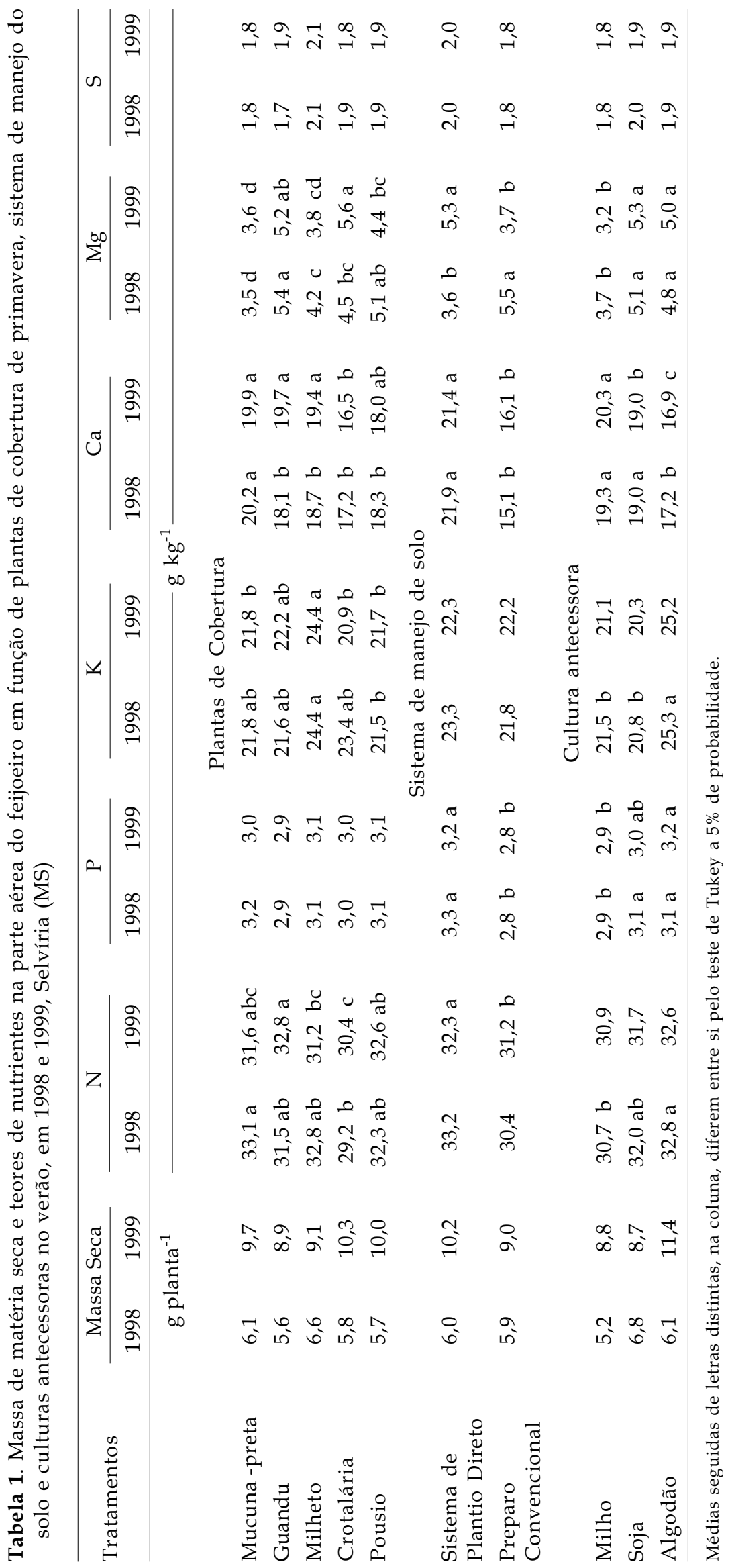


O milho como cultura anterior proporcionou menor absorção de $\mathrm{N}, \mathrm{P}$ e $\mathrm{Mg}$ pelo feijoeiro até o florescimento (Tabela 1), o que pode ter afetado negativamente a produção de massa seca. Nos tratamentos anteriores com milho, observou-se amarelecimento nos feijoeiros, sintoma típico de deficiência de nitrogênio, em função da elevada relação $\mathrm{C} / \mathrm{N}$ na fitomassa de milho (WUTKE et al., 1998); durante sua decomposição ocorre maior imobilização de nitrogênio, principalmente quando se incorpora ao solo. A mais lenta decomposição dos restos do milho, pode ter dificultado a disponibilização de nutrientes, notadamente o $\mathrm{P}$ e o $\mathrm{Mg}$, para o feijoeiro em sucessão. A sucessão ao milho proporcionou maiores teores de $\mathrm{Ca}$ ao feijoeiro, sendo em 1998 superior apenas ao algodão.

O cultivo anterior de algodão proporcionou os maiores teores na parte aérea do feijoeiro de N, P e $\mathrm{Mg}$, em comparação ao milho, de K em comparação a soja e ao milho e menores de Ca (Tabela 1). Tais resultados podem ser explicados pela maior dose de $\mathrm{P}_{2} \mathrm{O}_{5}$ e $\mathrm{K}_{2} \mathrm{O}$ aplicados na semeadura e pela pequena exportação de nutrientes dessa cultura.

Houve interação significativa entre sistema de manejo do solo e cultura antecessora para massa seca do feijoeiro, nos dois anos (Tabela 2). Nota-se que a incorporação dos restos da cultura do milho, mediante o preparo convencional do solo, promoveu menor produção de massa seca da parte aérea pelo feijoeiro em sucessão, em comparação ao sistema de plantio direto recém implantado, nas duas safras. Em 1999, o preparo convencional na área com o cultivo antecessor de soja, também proporcionou menor produção de massa seca do feijoeiro, em comparação ao tratamento em sucessão ao algodão.

Tabela 2. Efeito da interação entre sistema de manejo do solo e cultura antecessora referente à massa seca da parte aérea (g planta ${ }^{-1}$ ) de feijoeiros, em 1998 e 1999. UNESP, Ilha Solteira (SP), 2006

\begin{tabular}{lcc}
\hline \multirow{2}{*}{$\begin{array}{l}\text { Cultura } \\
\text { Antecessora }\end{array}$} & \multicolumn{2}{c}{ Sistema de Manejo do Solo } \\
\cline { 2 - 3 } & $\begin{array}{c}\text { Sistema de } \\
\text { Plantio Direto }\end{array}$ & $\begin{array}{c}\text { Sistema } \\
\text { Convencional }\end{array}$ \\
\hline Milho & 5,9 a A & 1998 \\
Soja & 6,1 a A & 4,5 b B \\
Algodão & 6,1 a A & 6,1 a A \\
\hline & & 6,9 a A \\
Milho & 10,2 a A & \\
Soja & 9,0 a A & 7,3 b B \\
Algodão & 11,4 a A & 8,4 b A \\
\hline
\end{tabular}

Médias seguidas de letras distintas, minúsculas nas colunas e maiúscula nas linhas, para cada desdobramento, diferem entre si pelo teste de Tukey a $5 \%$ de probabilidade
O uso das plantas de cobertura na primavera não teve influência nas características agronômicas, componentes da produção e produtividade de grãos do feijoeiro, dois anos de cultivo (Tabela 3), a exemplo do observado para produção de massa seca da parte aérea. Arf et al. (1996) e Silva (2005), trabalhando no mesmo tipo de solo, não verificaram efeitos dos tratamentos com plantas de cobertura nas características agronômicas e produtividade de grãos do feijoeiro. Wutke et al. (1998) e ARF et al. (1999) verificaram maior produtividade do feijoeiro de inverno cultivado em sucessão a plantas de cobertura, especialmente a mucuna-preta. Contudo, é importante mencionar nos trabalhos citados, que o feijoeiro foi cultivado logo após as plantas de cobertura, diferentemente ao que ocorreu na presente pesquisa, em que as espécies de plantas de cobertura foram cultivadas na primavera (outubro-novembro) e o feijoeiro foi semeado após as culturas de verão, ou seja, em junho do ano seguinte. Segundo Miyasawa et al. (1993), os efeitos dos resíduos vegetais das leguminosas na melhoria da fertilidade de solos ácidos são de curta duração, tendo grande importância na fase inicial da cultura subseqüente.

A maior tecnificação no cultivo do feijoeiro em grandes áreas tem levado a adoção de sistemas totalmente mecanizados na colheita da cultura do feijoeiro. Entre os fatores que exercem influência direta nas perdas e na pureza dos grãos na colheita mecanizada estão o porte ereto e, principalmente, a altura de inserção da primeira vagem.

Assim, plantas com essas características possibilitam a colheita mecânica, quando associadas à ausência de acamamento, com vantagens na colheita, e as alterações na arquitetura da planta podem ser provocadas por diferentes práticas de manejo. Em 1998 houve efeito da interação cultura antecessora $\mathrm{x}$ sistema de manejo do solo em relação à altura de planta (Tabela 4).

No sistema de plantio direto, recémimplantado, verificou-se menor altura nas plantas oriundas da área de milho, o que pode estar relacionado à menor disponibilidade e, conseqüente, menor absorção de nutrientes, principalmente, o N (Tabela 1). No preparo convencional, a menor altura foi verificada nas plantas com cultivo antecessor da soja, sendo esta inferior apenas às obtidas em sucessão ao algodão (Tabela 4). Contudo, o sistema de plantio direto recém-implantado favoreceu o desenvolvimento vegetativo, proporcionando a obtenção de plantas de feijoeiro mais altas, independentemente da cultura antecessora. 


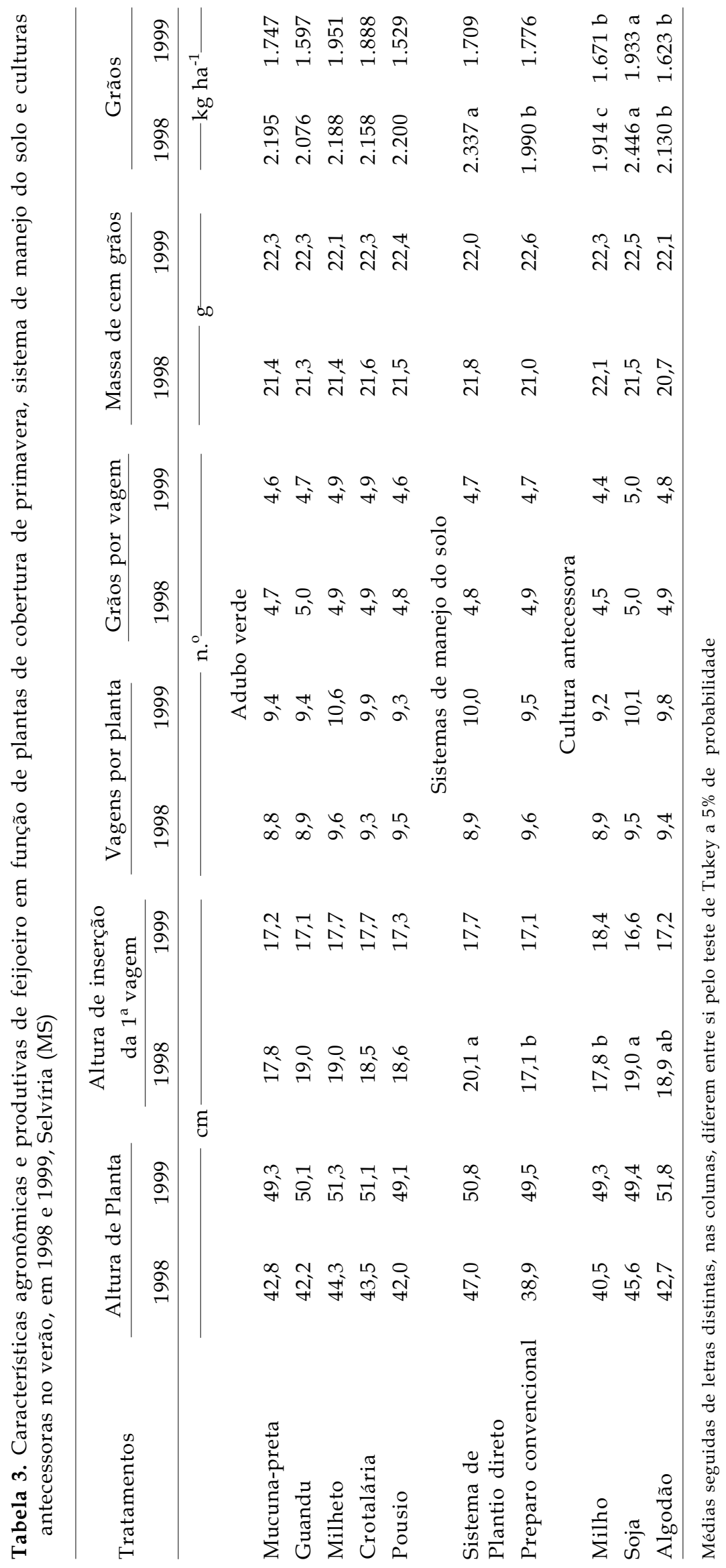


Tabela 4. Efeito da interação entre sistema de manejo do solo e cultura antecessora referente à altura de plantas, número de vagens por planta e massa de 100 grãos (1998) e altura de inserção da primeira vagem e número de grãos por vagem (1999), de feijoeiro. Selvíria (MS)

\begin{tabular}{|c|c|c|}
\hline \multirow{3}{*}{$\begin{array}{l}\text { Cultura } \\
\text { Antecessora }\end{array}$} & \multicolumn{2}{|c|}{ Sistema de Manejo do Solo } \\
\hline & \multirow{2}{*}{$\begin{array}{c}\text { Sistema de } \\
\text { Plantio Direto }\end{array}$} & \multirow{2}{*}{$\begin{array}{c}\text { Sistema } \\
\text { Convencional }\end{array}$} \\
\hline & & \\
\hline & \multicolumn{2}{|c|}{ Altura de plantas $(\mathrm{cm})-1998$} \\
\hline Milho & $42,2 \mathrm{~b} \mathrm{~A}$ & $38,0 \mathrm{ab} B$ \\
\hline Soja & 50,1 a $A$ & $36,5 \mathrm{~b} \mathrm{~B}$ \\
\hline \multirow[t]{2}{*}{ Algodão } & 48,8 a $\mathrm{A}$ & 41,9 a B \\
\hline & \multicolumn{2}{|c|}{ Número de grãos por vagem - 1998} \\
\hline Milho & $4,5 \mathrm{~b} \mathrm{~B}$ & 4,9 a $\mathrm{A}$ \\
\hline Soja & $4,9 \mathrm{ab} \mathrm{A}$ & 4,8 a $\mathrm{A}$ \\
\hline \multirow[t]{2}{*}{ Algodão } & 5,0 a $\mathrm{A}$ & 5,0 a $A$ \\
\hline & \multicolumn{2}{|c|}{ Massa de 100 grãos (g) - 1998} \\
\hline Milho & 23,1 a $\mathrm{A}$ & $21,1 \mathrm{ab} B$ \\
\hline Soja & 20,8 с A & $20,5 \mathrm{~b} \mathrm{~A}$ \\
\hline \multirow[t]{2}{*}{ Algodão } & $21,6 \mathrm{~b} \mathrm{~A}$ & 21,2 a $A$ \\
\hline & \multicolumn{2}{|c|}{$\begin{array}{c}\text { Altura de inserção } \\
\text { da primeira vagem (cm) - } 1999\end{array}$} \\
\hline Milho & 19,5 a $\mathrm{A}$ & 17,3 a B \\
\hline Soja & $16,1 \mathrm{~b} \mathrm{~A}$ & 17,1 a $A$ \\
\hline \multirow[t]{2}{*}{ Algodão } & $17,4 \mathrm{~b} \mathrm{~A}$ & 16,9 a A \\
\hline & \multicolumn{2}{|c|}{ Número de grãos por vagem - 1999} \\
\hline Milho & $4,5 \mathrm{~b} \mathrm{~A}$ & $4,3 \mathrm{~b} \mathrm{~A}$ \\
\hline Soja & 5,2 a $A$ & 4,9 a $\mathrm{A}$ \\
\hline Algodão & $4,5 \mathrm{ab} B$ & 5,1 a $A$ \\
\hline
\end{tabular}

Médias seguidas de letras distintas, minúsculas nas colunas e maiúscula nas linhas, para cada componente de produção avaliado, diferem entre si pelo teste de Tukey a $5 \%$ de probabilidade.

O crescimento do feijoeiro tem sido favorecido pelo sistema de plantio direto, mesmo em condições irrigadas, por proporcionar maior armazenamento de água (URCHEI, 1996; STONE e SILVEIRA, 1999), afetado entre outros fatores, pelo aumento dos microporos na camada superficial do solo sob esse sistema de manejo, devido à maior densidade (Figura 1). Em 1999, a altura de plantas não foi influenciada pela cultura antecessora e pelo sistema de manejo.

Quanto à altura de inserção da primeira vagem, houve efeito do manejo do solo e da cultura antecessora, no primeiro ano de cultivo (Tabela 3 ). No sistema de plantio direto observou-se maior valor para essa característica. $\mathrm{O}$ cultivo do feijoeiro em sucessão ao milho, semelhante ao que ocorreu para a altura de plantas, promoveu a obtenção de plantas com altura de inserção da primeira vagem menores, diferindo apenas do tratamento onde foi cultivada anteriormente à soja. Em 1999, ocorreu efeito significativo da interação sistema de manejo do solo x cultura antecessora para altura de inserção da primeira vagem; no sistema de plantio direto, com o cultivo do feijoeiro após a cultura do milho, verificou-se a maior média. Já no preparo convencional, não foi observado efeito da cultura anterior (Tabela 4). No que se refere ao sistema de manejo do solo, constata-se que apenas no tratamento onde anteriormente foi cultivado o milho no verão, o sistema de plantio direto proporcionou maior altura de inserção da primeira vagem.

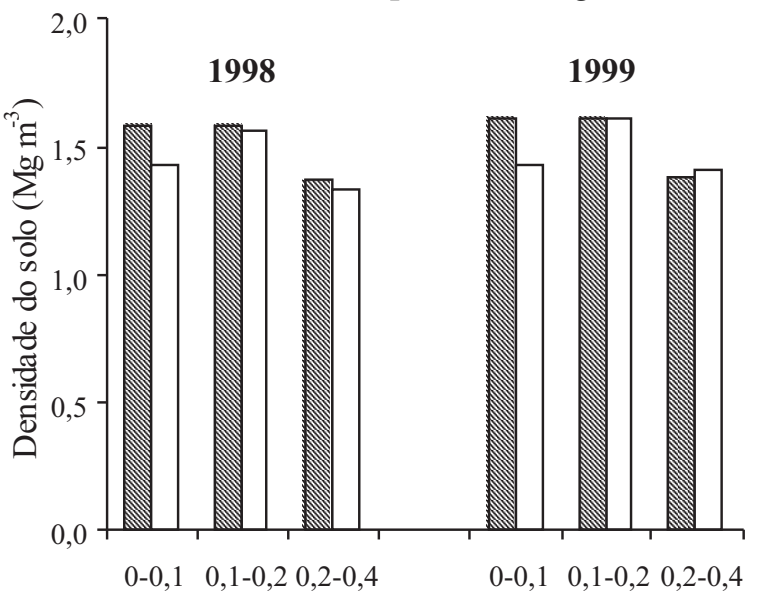

Figura 1. Densidade do solo (Mg m-3) em razão do sistema de plantio direto $(\mathbb{Z})$ e preparo convencional $(\square)$, após a colheita do feijoeiro, nos anos de 1998 e 1999. UNESP, Ilha Solteira,

O número de vagens por planta não foi afetado por nenhum dos fatores estudados (Tabela 3). ARF et al. (1996) também não verificaram efeito da adubação verde sobre essa característica. SiLva (2005) observou números semelhantes de vagens por planta do feijoeiro cultivado após milho, arroz ou soja. Em relação ao sistema de manejo do solo, existem estudos sobre as diferenças nos sistemas de manejo, como o de Stone e Moreira (2000), em estudo de quatro anos avaliando sistema de semeadura e lâmina de água aplicada, os quais verificaram maiores valores desse componente da produção sob sistema de plantio direto, com adequada cobertura do solo, em comparação ao preparo convencional; também há estudos cujo sistema de semeadura direta foi semelhante ou inferior ao sistema convencional ou outros sistemas para este componente da produção, como os de Stone e Moreira (2001), Soratto et al. (2003) e Silva (2005).

Quanto ao número de grãos por vagem, houve efeito significativo da interação sistema de manejo do solo x cultura antecessora, nos dois anos de cultivo (Tabela 4). Verifica-se que o cultivo anterior do milho, no sistema de plantio direto, proporcionou menor valor dessa característica, não diferindo da área com soja no verão, em 1998. Já no segundo ano, o milho como cultura antecessora promoveu menor número de grãos por vagem do feijoeiro, em ambos os sistemas de manejo do solo, porém, sem diferir do tratamento com algodão, no sistema de plantio direto. Todavia, 
verifica-se que em 1999, a incorporação dos restos da cultura do algodão, mediante o preparo convencional aumentou o valor desse componente da produção.

Para a massa de cem grãos, houve efeito significativo da interação cultura antecessora $x$ sistema de manejo do solo, no primeiro ano de cultivo (Tabela 4). Verificou-se que nos sistema de plantio direto o maior valor foi observado nos grãos produzidos com cultivo anterior de milho. No preparo convencional a maior massa de grãos foi verificada com cultivo anterior de algodão, diferindo somente da área de soja. A menor massa de grãos observada na área em sucessão à soja (Tabela 4), nos dois sistemas de manejo do solo, pode estar relacionada com o fato de que nessa condição obteve-se maior número de grãos por vagem. A faixa de massa de cem grãos observada no presente experimento $(20,59$ a $23,16 \mathrm{~g})$ para a cultivar IAC Carioca foi semelhante à verificada por ARF et al. (1999), que observaram, respectivamente, para massa de cem grãos da mesma cultivar variações de 22,16 a 23,50 e 19,5 a 22,5 g. No segundo ano de cultivo, essa variável não foi influenciada pelos tratamentos (Tabela 3).

O sistema de manejo do solo afetou a produtividade de grãos do feijoeiro apenas no primeiro ano de cultivo (Tabela 3). Apesar de ter promovido certa redução na densidade do solo (Figura 1), o preparo convencional proporcionou menor produtividade do feijoeiro, o que pode estar relacionada com o menor acúmulo de nutrientes (Tabela 1). Tais resultados estão de acordo com as observações de UrChei (1996) e Stone e Silveira (1999). Esses autores verificaram que o preparo convencional do solo, em condições irrigadas, proporcionou ao feijoeiro menor produtividade, em relação ao sistema de plantio direto. Segundo Stone e Silveira (1999), essa menor produtividade foi verificada, mesmo tendo o revolvimento do solo promovido menor resistência do solo à penetração e melhor distribuição do sistema radicular do feijoeiro. Além da maior disponibilidade de água, a maior produtividade em sistema de plantio direto tem sido atribuída também ao acúmulo de nutrientes na camada superficial e à maior atividade biológica, condicionada pela maior umidade e menor temperatura do solo, com reflexos na solubilização, na liberação de nutrientes e na eficiência da absorção pelas plantas (Stone e Silveira, 1999; UrChei, 1996). Segundo Rheinheimer et al. (1998), no sistema de plantio direto, o não-revolvimento, a manutenção e a gradual decomposição dos restos de culturas na superfície do solo resultam em menor perda de solo por erosão, menor mistura dos fertilizantes com o solo e, conseqüentemente, acúmulo de nutrientes na camada superficial, além da manutenção do P em forma disponível por maior período, devido à competição de compostos orgânicos pelos sítios de adsorção, facilitando a absorção pelas culturas.

A sucessão de culturas teve influência na produtividade de grãos, nos dois anos, com os maiores valores obtidos no cultivo do feijoeiro após soja (Tabela 3). O cultivo do feijoeiro após soja proporcionou, em média, produtividade de grãos $22,1 \%$ e $16,7 \%$ superiores a sucessões com milho e algodão respectivamente. A maior produtividade observada com cultivo anterior de soja pode estar relacionada com a menor relação $\mathrm{C} / \mathrm{N}$ nos restos dessa cultura. É provável que a disponibilização mais rápida do $\mathrm{N}$, coincidindo com o período de exigência da cultura (Oliveira et al., 2002), tenha sido o fator que propiciou a maior produtividade grãos pelo feijoeiro cultivado após a leguminosa. Nos tratamentos anteriores com milho, observou-se amarelecimento na cultura do feijoeiro, sintoma típico da deficiência de nitrogênio, que deve ter ocorrido como efeito imediato da incorporação de material orgânico com alta relação C/ $\mathrm{N}$, causando a imobilização do nitrogênio assimilável do solo. ARF et al. (1999) também verificaram maior produtividade do feijoeiro em sucessão a leguminosas, em comparação ao cultivo após milho.

\section{CONCLUSÕES}

1. As plantas de cobertura influenciam o acúmulo de nutrientes, mas não interferem nas características agronômicas e produtividade do feijoeiro de outono-inverno.

2. A produtividade do feijoeiro de outonoinverno é maior na sucessão à cultura da soja, que em sucessão ao algodão ou milho.

\section{AGRADECIMENTOS}

À Fapesp, pela concessão de bolsa de Doutorado a Marco Antonio Camillo de Carvalho e subvenção do trabalho.

\section{REFERÊNCIAS}

ARF, O.; SÁ, M.E. de; BUZETTI, S. Incorporação de mucunapreta e de restos culturais de milho antes da cultura do feijão (Phaseolus vulgaris L.) de inverno. Pesquisa Agropecuária Brasileira, Brasília, v.31, n.8, p.563-568, 1996.

ARF, O.; SILVA, L.D. da; BUZETTI, S.; ALVES, M.C.; SÁ, M.E. de; RODRIGUES, R.A.F.; HERNANDEZ, F.B.T. Efeito da rotação de culturas, adubação verde e nitrogenada sobre o rendimento do feijão. Pesquisa Agropecuária Brasileira, Brasília,v.34, n.11, p.2029-2036, 1999. 
CONAB - CONSELHO NACIONAL DE ABASTECIMENTO (Brasília, DF). Safras 1990/1991 a 2004/2005: série histórica. Disponível em: <http://www.conab.gov.br/safras.asp>. Acesso em: 12 dez. 2005.

DEMATTÊ, J.L.I. Levantamento detalhado dos solos do "Campus Experimental de Ilha Solteira". Piracicaba: Departamento de Solos, Geologia e Fertilidade, ESALQ/USP, 1980. p.11-31.

EMBRAPA - EMPRESA BRASILEIRA DE PESQUISA AGROPECUÁRIA. Banco de dados climáticos do Brasil. Disponível em: http://www.bdclima.cnpm.embrapa.br. Acesso em: 25 jan. 2007.

HERNANI, L.C.; ENDRES, V.C.; PITOL, C.; SANTON, J.C. Adubos verdes de outono/inverno no Mato Grosso do Sul. Dourados: Embrapa-CPAO, 1995. 93p.

HERNANI, L.C.; SALTON, J.C.; FABRÍCIO, A.C.; DEDECEK, R.; ALVES JÚNIOR, A. Perdas por erosão e rendimentos de soja e trigo em diferentes sistemas de preparo de um Latossolo Roxo de Dourados (MS). Revista Brasileira de Ciência do Solo, Viçosa, v.21, n.4, p.667-676, 1997.

IGUE, K. Dinâmica da matéria orgânica e seus efeitos nas propriedades do solo. In: ADUBAÇÃO verde no Brasil. Campinas: Fundação Cargill, 1984. p.232-267.

KIEHL, E. J. Manual de Edafologia. São Paulo: Ceres, 1979. 262 p.

KLUTHCOUSKI, J.; FANCELLI, A.L.; DOURADO NETO, D.; RIBEIRO, C.R.; FERRARO, L.A. Manejo do solo e o rendimento de soja, milho, feijão e arroz em plantio direto. Scientia Agricola, Piracicaba, v.57, n.1 p.97-104, 2000.

MALAVOLTA, E.; VITTI, G.C.; OLIVEIRA, S.A. Avaliação do estado nutricional das plantas: princípios e aplicações. 2.ed. Piracicaba: Potafos, 1997. 319p.

MIYAZAWA, M.; PAVAN, M.A.; CALEGARI, A. Efeito de material vegetal na acidez do solo. Revista Brasileira de Ciência do Solo, Campinas, v.17, p.411-416, 1993.

OLIVEIRA, T.K.; CARVALHO, G.J.; MORAES, R.N.S. Plantas de cobertura e seus efeitos sobre o feijoeiro em plantio direto. Pesquisa Agropecuária Brasileira, Brasília, v.37, n.8, p.10791087, 2002.

RAIJ, B.van; CANTARELLA, H.; QUAGGIO, J.A.; FURLANI, M.A.C. Recomendações de adubação e calagem para o Estado de São Paulo 2.ed. Campinas: Instituto Agronômico \& Fundação IAC, 1996. 285 p. (Boletim IAC, 100)

RHEINHEIMER, D.S.; KAMINSKI, J.; LUPATINI, G.C.; SANTOS, E.J.S. Modificações em atributos químicos de solo arenoso sob sistema de plantio direto. Revista Brasileira de Ciência do Solo, Viçosa, v.22, n.4, p.713-721, 1998.

SALTON, J.C.; HERNANI, L.C. Cultivos de primavera: alternativas para produção de palha no Mato Grosso do Sul. In: REUNIÃO BRASI-LEIRA DE MANEJO E CONSERVAÇÃO DO SOLO, 10., Florianópolis, 1994. Resumos... Florianópolis: SBCS, 1994. p.248-249.
SANCHEZ, P.A.; LOGAN, T.J. Myths and science about the chemistry and fertility of soils in the tropics. In: LAL, R.; SANCHEZ, P.A. (Ed.). Myths and science of soil of the tropics. Madison: Soil Science Society of America, 1992. p.35-46. (Special Publication, 29)

SILVA, M.G. Sucessão de culturas e preparo do solo no desenvolvimento e produtividade do feijoeiro cultivado no período de inverno. 2005. 89p. Dissertação (Mestrado) Universidade Estadual Paulista, Ilha Solteira, 2005.

SILVA, M.G.; ARF, O.;SÁ, M.E.; RODRIGUES, R.A.F.; BUZETTI, $S$. Nitrogen fertilization and soil management of winter common bean crop. Scienta Agricola, Piracicaba, v.61, n.3, p. 307-312, 2004

SILVEIRA, P.M.;SILVA, O.F.;STONE, L.F.;SILVA, J.G. Efeitos do preparo do solo, plantio direto e de rotações de culturas sobre o rendimento e a economicidade do feijoeiro irrigado. Pesquisa Agropecuária Brasileira,Brasília, v. 36, n.2, p. 257-263, 2001.

SORATTO, R.P.; ARF, O.; RODRIGUES, R.A.F.; BUZETTI, S.; SÁ, M.E.; SILVA, T.R.B. Resposta do feijoeiro ao preparo do solo, manejo de água e parcelamento do nitrogênio. Acta Scientiarum: Agronomy, v. 25, n.1, p.89-96, 2003.

STONE, L.F.; MOREIRA, J.A.A. Efeitos de sistemas de preparo do solo no uso da água e na produtividade do feijoeiro. Pesquisa Agropecuária Brasileira, Brasília, v. 35, n.4, p. 835-841, 2000.

STONE, L.F.; MOREIRA, J.A.A. Resposta do feijoeiro ao nitrogênio em cobertura, sob diferentes lâminas de irrigação e preparos do solo. Pesquisa Agropecuária Brasileira, Brasília, v. 36, n.3, p. 473-481, 2001.

STONE, L.F.; SILVEIRA, P.M. da. Efeitos do sistema de preparo na compactação do solo, disponibilidade hídrica e comportamento do feijoeiro. Pesquisa Agropecuária Brasileira, Brasília, v.34, n.1, p.83-91, 1999.

URCHEI, M.A. Efeitos do plantio direto e do preparo convencional sobre alguns atributos físicos de um Latossolo Vermelho escuro argiloso e no crescimento e produtividade do feijoeiro (Phaseolus vulgaris L.) sob irrigação. 1996. 131p. Tese (Doutorado) Universidade Estadual Paulista, Botucatu, 1996.

WUTKE, E.B. Adubação verde: manejo da fitomassa e espécies utilizadas no Estado de São Paulo. In: WUTKE, E.B.; BULISANE, E.A.; MASCARENHAS, H.A.A. (Coord.). Curso sobre adubação verde no Instituto Agronômico. Campinas: Instituto Agronômico, 1993. p.17-29. (Documentos, 35)

WUTKE, E.B.; FANCELLI, A.L.; PEREIRA, J.C.V.N.A.; AMBROSANO, G.M.B. Rendimento do feijoeiro irrigado em rotação com culturas graníferas e adubos verdes. Bragantia, Campinas, v.57, n.2, p.325-338, 1998. 